\title{
Collisionally Activated Dissociation Mass Spectrometric Analysis of Alkali Halide Triple Ion Adduct Monosaccharide Ions ${ }^{\dagger}$
}

\author{
Nora Martinez, ${ }^{\text {*b) }}$ Kimio IsA, ${ }^{\text {a) }}$ Minoru Hatanaka, \\ and Ryuji NAKATA ${ }^{\text {a) }}$
}

(Received September 20, 2002; Accepted December 24, 2002)

\begin{abstract}
Adduct ions of monosaccharide molecules with alkali halide triple ions were analyzed by Fast Atom Bombardment (FAB) and Collisionally Activated Dissociation (CAD) techniques. The adduct ions generally appeared in the form of $[\mathrm{S}+\mathrm{AiXAj}]^{+}$, where $\mathrm{S}=$ monosaccharide molecule, $\mathrm{Ai}^{+}=\mathrm{Na}^{+}, \mathrm{Aj}^{+}=\mathrm{Cs}^{+}$, and $\mathrm{X}^{-}=\mathrm{Cl}^{-}$, respectively. First, in FABMS spectra, $(\mathrm{AiXAj})^{+}$adduct monosaccharide molecule ions were identified; second, from the mass spectra, the precursor ions were selected, and it was possible to verify their product ions in the CAD spectra. Then, the relative intensities of the product ions were compared. In the present paper, we report the fragmentation processes of $[\mathrm{S}+\mathrm{AiXAj}]^{+}$, the main $(\mathrm{AiXAj})^{+}, \mathrm{Ai}^{+}, \mathrm{Aj}^{+},(\mathrm{S}+\mathrm{Ai})^{+},(\mathrm{S}+\mathrm{Aj})^{+}$product ions, the relative intensities of these product ions, and try to explain the interactions occurring in $[\mathrm{S}+\mathrm{AiXAj}]^{+}$adduct ions.
\end{abstract}

\section{Introduction}

In the past several decades, mass spectrometric analysis has been extensively used to analyze chemical compounds as well as to characterize unknown compounds in organic, biotechnological, and pharmaceutical chemistry. Moreover, mass spectrometry is becoming one of the main tools for detection and analysis of environmental pollutants due to its ease of manipulation, high speed, high accuracy, high resolution, and high sensitivity.

At present, the current methods for carbohydrate structural analysis are nuclear magnetic resonance (NMR), enzymatic reduction, permethylation-hydrolysis, gas chromatography/mass spectrometry (GC/MS) and matrix-assisted laser desorption ionization/time of flight mass spectrometry (MALDI/TOFMS). Some recent studies have been reported on oligosaccharide fragmentations using MALDI/TOFMS. ${ }^{1)}$, 2) The stereochemical differentiation of some monosaccharides using electrospray ionization (ESI) ion trap mass spectrometry has been carried out by J. A. Leary and colleagues $^{3)}$ where tandem mass spectrometry (MS/ $\mathrm{MS}$ ) is employed to probe carbohydrate structure. Also, the determination of linkage position and anom-

a) Laboratory of Natural Science Education, Faculty of Education and Regional Studies, Fukui University (Bunkyo 3-91, Fukui 910-8507, Japan)

*b) Department of Material Engineering, Graduate School of Engineering, Fukui University (Bunkyo 3-9-1, Fukui 9108507, Japan) eric configuration in glucose-containing disaccharide alditols have been previously reported by GC/MS analysis. ${ }^{4)}$

The most recent studies using FABMS and FABMS/ MS have provided information on linkage types, monosaccharide molecule substitution patterns, glycoconjugate structures, ${ }^{5)}$ etc. However, there is not much previous research on simple carbohydrates bound to alkali metal ions or to alkali metal triple ions. Also, there is not much literature on alkali metal ion affinities reported for mono- or oligosaccharides. Alkali cations binding to carbohydrates have been reported in the instance of $\mathrm{Na}^{+}$bound to a small number of monosaccharides using Fourier transform mass spectrometry (FTMS). ${ }^{6)}$ The existence, ion structures, fragmentation processes, and relative abundances of alkali halide triple ions in the gas-phase have been studied by FAB and $\mathrm{CAD}$, and reported in a previous work by our group, ${ }^{7)}$ however, scarce information is found on the interactions between single monosaccharide molecules and alkali halide or alkali halide triple ions, and the characteristic fragmentation processes of alkali halide triple ion adduct monosaccharide molecule ions by CAD.

One of the purposes of this study is to investigate, under these measurement conditions in the gas phase, how fragmentation occurs for the selected alkali halide triple ion adduct monosaccharide molecule ions, $(\mathrm{S}+$ $\mathrm{AiXAj})^{+}\left(\mathrm{Ai}^{+}=\mathrm{Na}^{+}, \mathrm{Aj}^{+}=\mathrm{Cs}^{+}, \mathrm{X}^{-}=\mathrm{Cl}^{-}\right)$, by the use of positive ion FABMS and CAD.

As it is known, carbohydrates play a crucial role for living organisms; they occur in nature in numerous

\footnotetext{
† Congratulations on winning the 2002 Nobel Prize

Dedicated to Professor John B. Fenn, awarded the 2002 Nobel Prize in Chemistry, in honor of his many seminal contributions to mass spectrometry and development of methods for identification and structural analyses of biological macromolecules.
} 
forms and are involved in a great variety of cellular interactions. For that reason, in order to find through FABMS and CAD data some useful information in the knowledge of gas-phase fragmentation processes of carbohydrates (e.g. dehydration), we selected a number of typical monosaccharides like glucose, mannose, galactose, fucose, and rhamnose due to their biological relevance. We then investigated their main adduct ions and their product ions as well as the binding interactions between these monosaccharide molecules and the alkali halide triple ions.

In the $\mathrm{CAD}$ spectra of $(\mathrm{S}+\mathrm{AiXAi})^{+},(\mathrm{S}+\mathrm{AiXAj})^{+}$, and $(\mathrm{S}+\mathrm{AjXAj})^{+}$adduct ions, it was possible to detect $(\mathrm{AiXAi})^{+},(\mathrm{AiXAj})^{+},(\mathrm{AjXAj})^{+}, \mathrm{Ai}^{+}, \mathrm{Aj}^{+},(\mathrm{S}+\mathrm{Ai})^{+}$, and $(\mathrm{S}$ $+\mathrm{Aj})^{+}$product ions. It is interesting to note that in most of $\mathrm{CAD}$ spectra, product ions like $(\mathrm{AiXAj})^{+}$are the strongest, and that, in the spectra of $(\mathrm{S}+\mathrm{NaClNa})^{+}$ions, some of predominant peaks were corresponding to water molecule loss. This is unlike the case of $(\mathrm{S}+$ $\mathrm{CsClCs})^{+}$fragmentation, in which water loss from the precursor ions is hardly observed.

\section{Experimental Section}

Measurements were performed using both types of mass spectrometers: JEOL DX-303 EBE and JMS 700T $\mathrm{BEBE}(\mathrm{E}=$ electric sector, $\mathrm{B}=$ magnetic sector). The JMS 700T BEBE is a fully automatic controlled foursector tandem MS system. The EBE measurement conditions have been previously described. ${ }^{7)}$ 8) Briefly, glycerol $(\mathrm{G})$ was used as the liquid matrix for FAB ionization (FAB + ion mode). Argon and xenon gases with atom gun energies of $6 \mathrm{keV}$ were used. The FAB gun emission currents were set at 20 and $3 \mathrm{~mA}$, respectively. The ion-accelerating voltages were set to $3 \mathrm{kV}$ and $10 \mathrm{kV}$, respectively. The pressure of argon gas was maintained at approximately $10^{-5}$ Torr $\left(10^{-3} \mathrm{~h} \mathrm{~Pa}\right)$. The mass resolution was approximately 1,000. In both $\mathrm{EBE}$ and BEBE MS/MS measurements, argon was used as a collision gas, and was supplied to the collision cell until the precursor ion peak was reduced to approximately $1 / 3$. Perfluoroalkyl phosphazine was used for mass calibration.

Samples were the following: L-rhamnose (Rha, $\mathrm{MW}=$
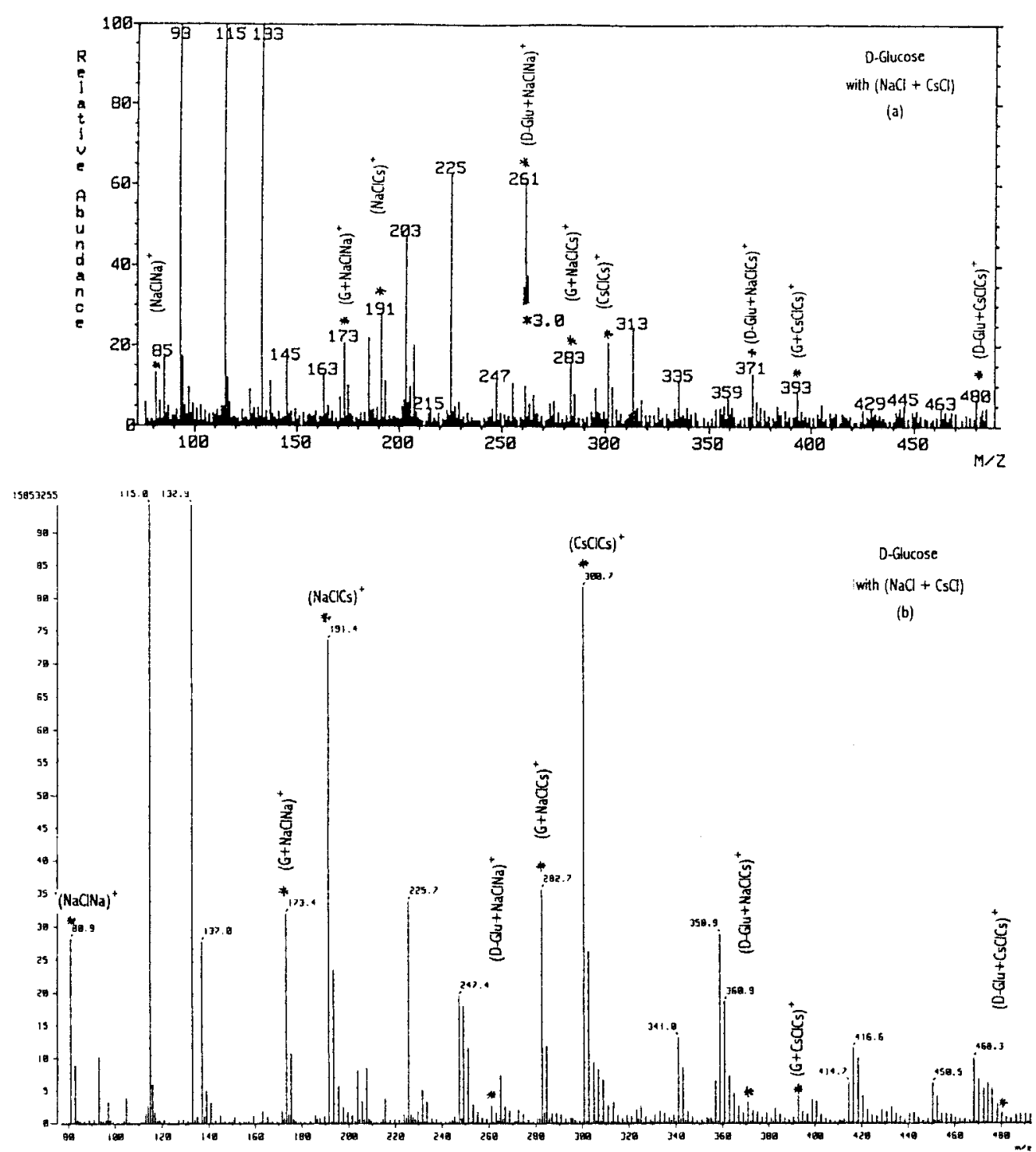

Fig. 1. FAB mass spectra of D-Glucose with $\mathrm{NaCl}$ and $\mathrm{CsCl}$ in glycerol matrix showing the main adduct ions obtained by (a) EBE and (b) BEBE type instruments. 

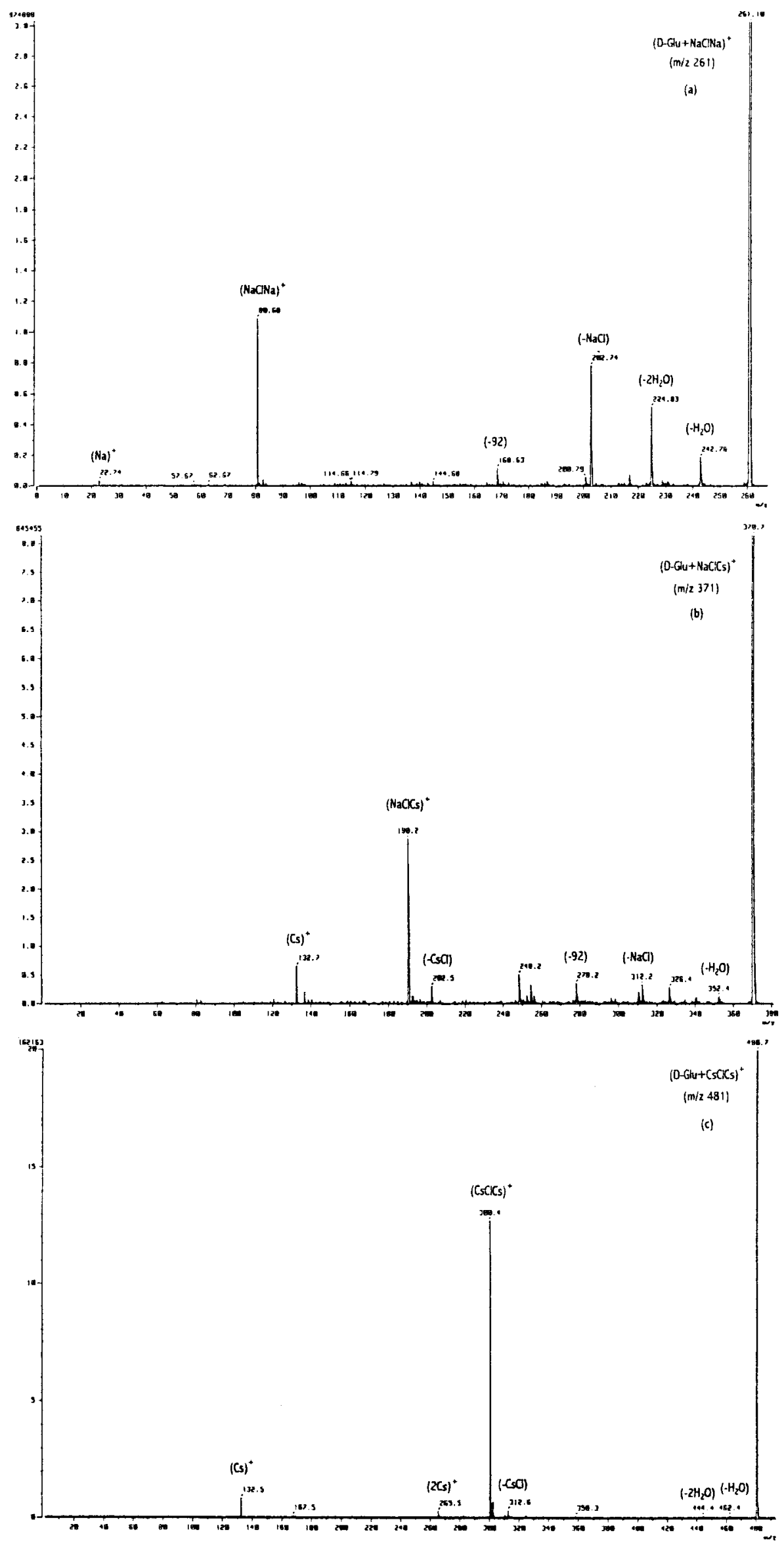

Fig. 2. The FABMS/MS spectra of (a) (D-Glu $+\mathrm{NaClNa})^{+}(m / z 261)$, (b) $(\mathrm{D}-\mathrm{Glu}+\mathrm{NaClCs})^{+}(m / z$ 371), and (c) (D-Glu + $\mathrm{CsClCs})^{+}(m / z 481)$ obtained by a BEBE-type instrument. 


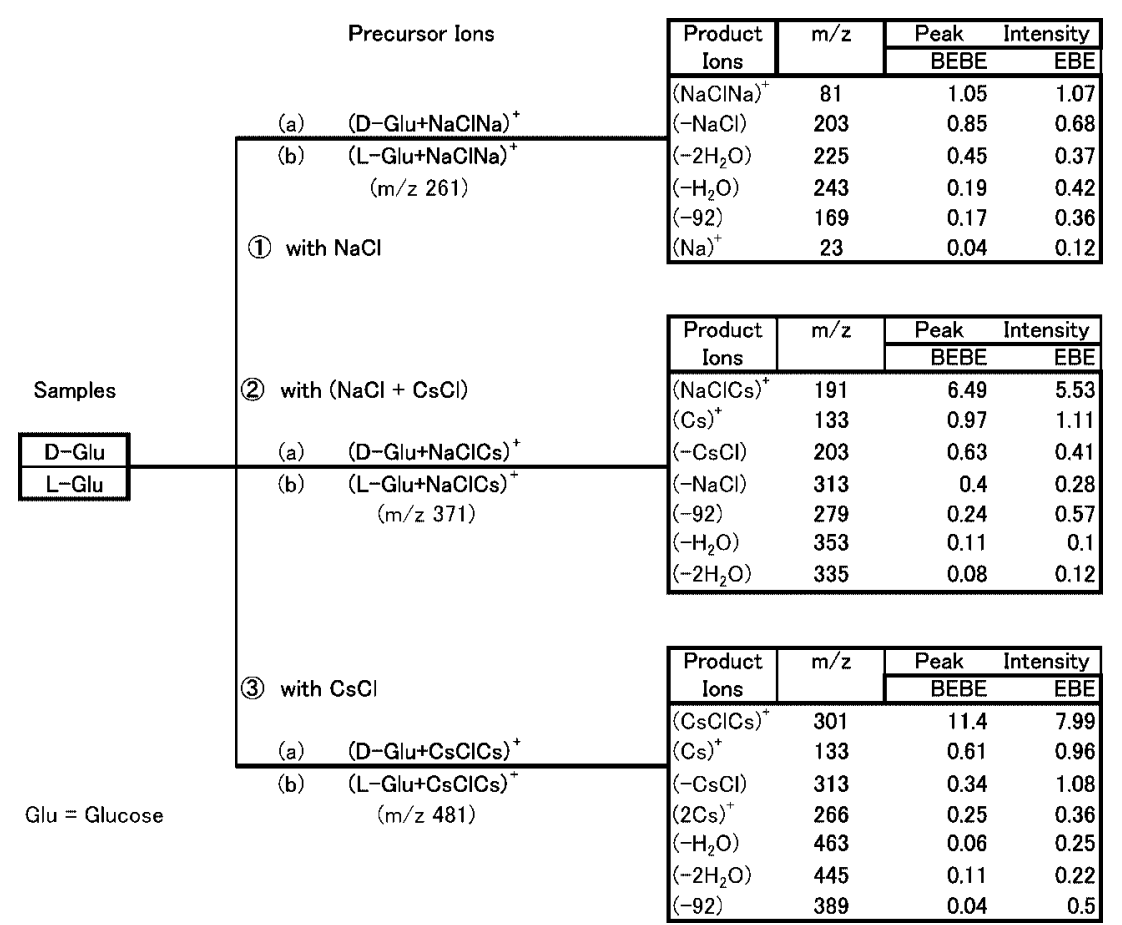

Fig. 3a. Peak intensities of product ions from $(\mathrm{Glu}+\mathrm{NaClNa})^{+}(\mathrm{m} / z 261),(\mathrm{Glu}+\mathrm{NaClCs})^{+}(\mathrm{m} / z 371)$, and $(\mathrm{Glu}+\mathrm{CsClCs})^{+}$ $(m / z 481)$ obtained by CAD.

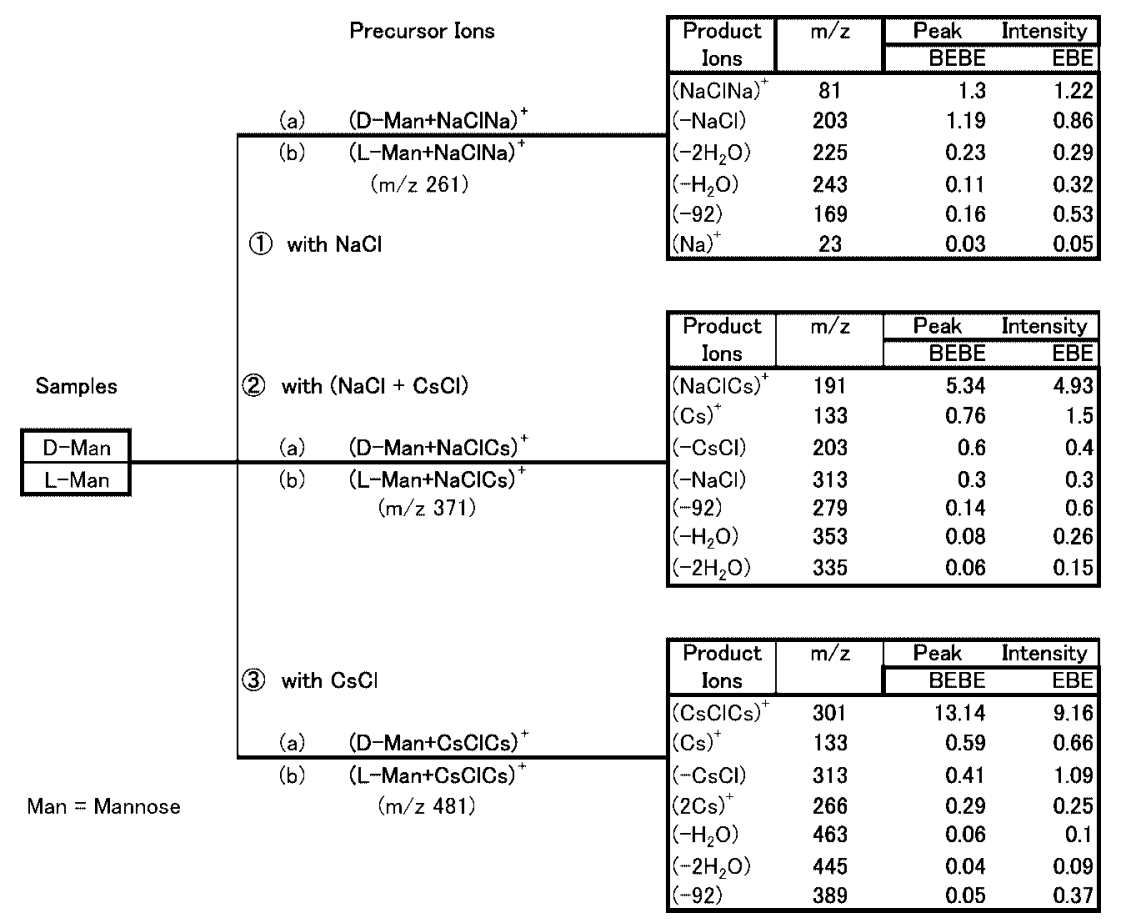

Fig. 3b. Peak intensities of product ions from $(\mathrm{Man}+\mathrm{NaClNa})^{+}(m / z 261),(\mathrm{Man}+\mathrm{NaClCs})^{+}(m / z 371)$, and $(\mathrm{Man}+\mathrm{CsClCs})^{+}$ $(m / z 481)$ obtained by CAD.

164), D- and L-glucose (Glu, MW=180), D- and Lgalactose (Gal, MW=180), D- and L-mannose (Man, MW $=180$ ), and $\mathrm{D}$ - and L-fucose (Fuc, MW = 164). The monosaccharides such as L-Gal, L-Glu, L-Man, and L-Rha were purchased from Tokyo Kasei Kogyo Co., Ltd.; D- and L-Fuc were obtained from Kanto Chemical Co., Inc.; D-Man was provided by Wako Pure Chemical Industries Ltd.; D-Gal and D-Glu were obtained from Sigma Chemical Co. (Japan). $\mathrm{NaCl}$ was purchased from Wako Pure Chemical Industries, and $\mathrm{CsCl}$ was obtained from
Kanto Chemical Co., Inc. Glycerol liquid matrix was purchased from Kanto Chemical Co., Inc. All samples were analytical grade and used without further purification.

Alkali halide salts were separately weighed and dissolved in water forming a $1 \mathrm{M}$-alkali halide solution, then, an aliquot of this solution (or a mixture of $\mathrm{NaCl}$ and $\mathrm{CsCl}$ ) was combined with the monosaccharide sample. Finally, this sample, dissolved in the liquid matrix (glycerol), was deposited on stainless steel 


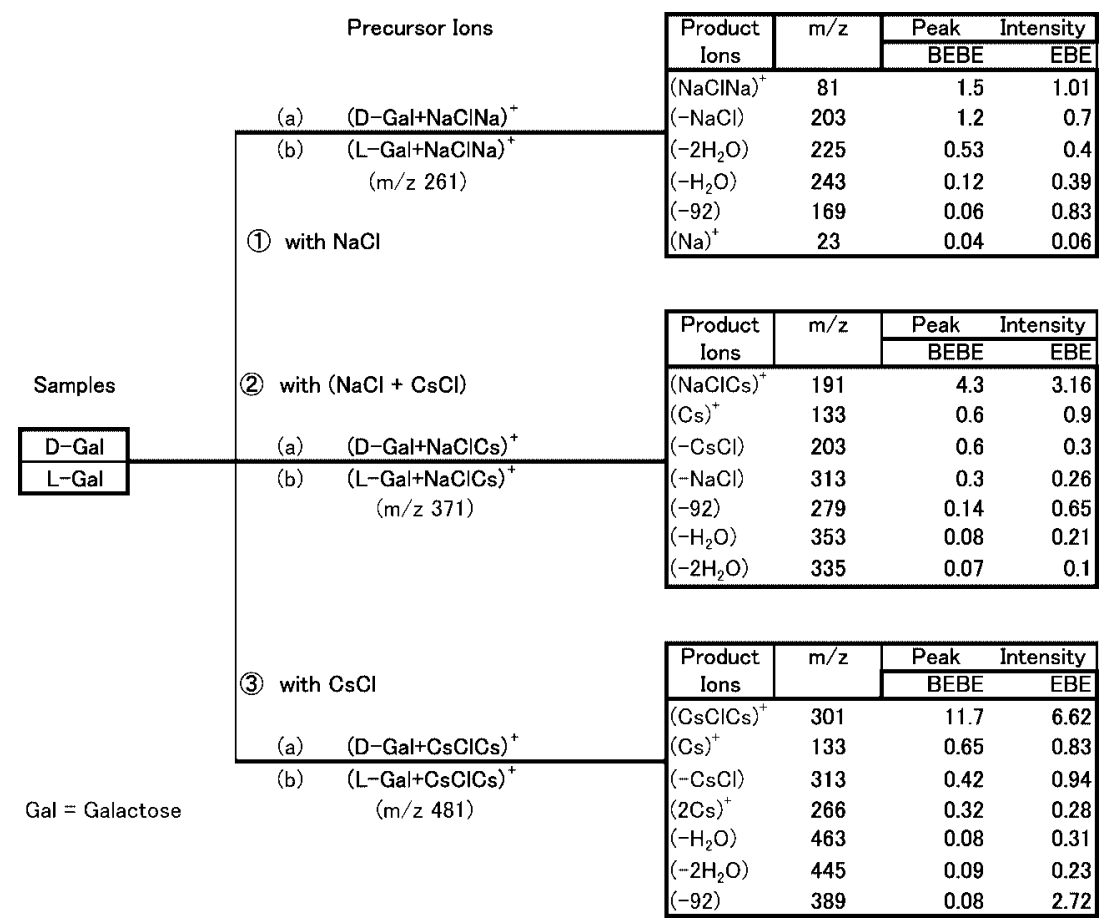

Fig. 3c. Peak intensities of product ions from $(\mathrm{Gal}+\mathrm{NaClNa})^{+}(m / z 261),(\mathrm{Gal}+\mathrm{NaClCs})^{+}(m / z 371)$, and $(\mathrm{Gal}+\mathrm{CsClCs})^{+}$ $(m / z 481)$ obtained by CAD.

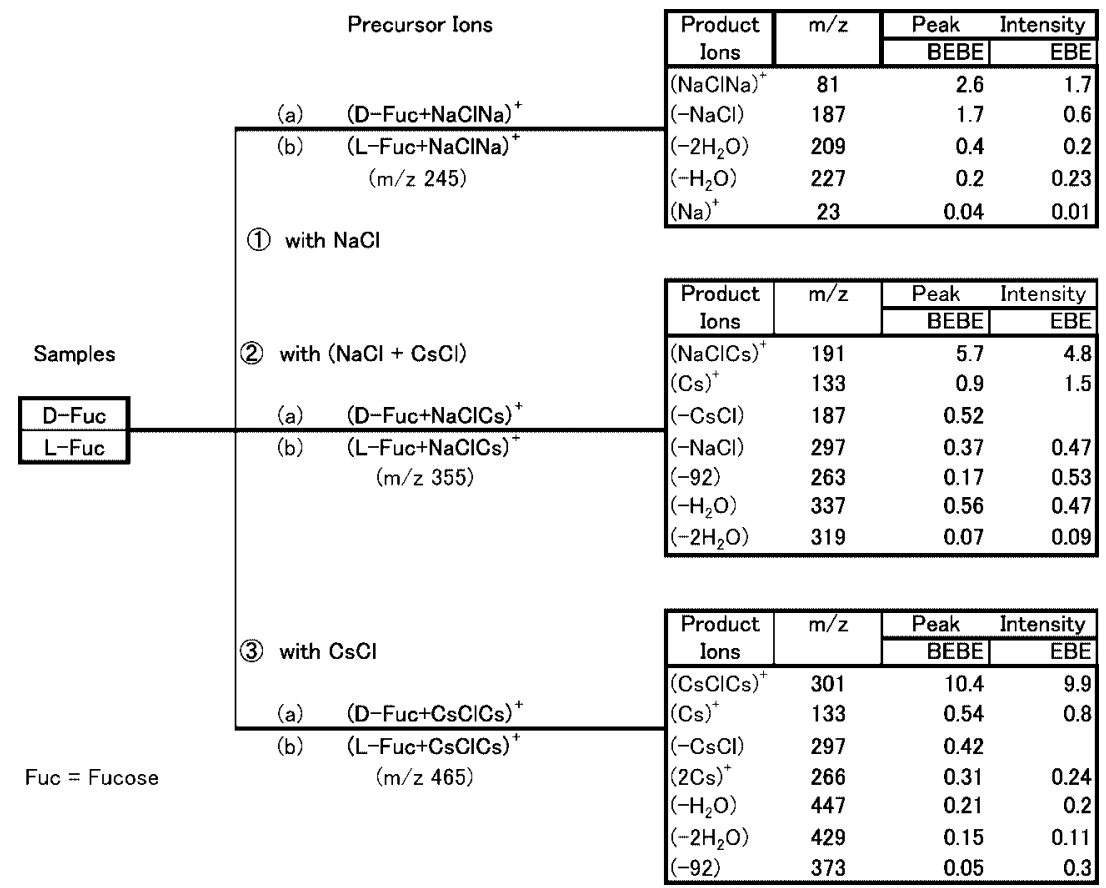

Fig. 3d. Peak intensities of product ions from $(\mathrm{Fuc}+\mathrm{NaClNa})^{+}(\mathrm{m} / z 245)$, $(\mathrm{Fuc}+\mathrm{NaClCs})^{+}(m / z 355)$, and $(\mathrm{Fuc}+\mathrm{CsClCs})^{+}$ $(m / z$ 465) obtained by CAD.

probe tips and introduced into the ion source target for measurement.

\section{Results and Discussion}

By utilizing the FABMS method, in both EBE and $\mathrm{BEBE}$ type instruments, the main $(\mathrm{S}+\mathrm{NaClNa})^{+},(\mathrm{S}+$ $\mathrm{NaClCs})^{+}$, and $(\mathrm{S}+\mathrm{CsClCs})^{+}$peaks were detected. As shown in Fig. 1, the peaks like $(\mathrm{Glu}+\mathrm{NaClCs})^{+}$were weaker than those of the $(\text { glycerol }+\mathrm{NaClCs})^{+}$peaks. This result may suggest that it is more difficult to add the triple ion to a monosaccharide molecule than to a glycerol molecule.

Using the CAD method, when the $(\mathrm{D}-\mathrm{Glu}+\mathrm{NaClNa})^{+}$ $\left(m / z\right.$ 261), $(\mathrm{D}-\mathrm{Glu}+\mathrm{NaClCs})^{+}(m / z 371)$, and $(\mathrm{D}-\mathrm{Glu}+$ $\mathrm{CsClCs})^{+}(m / z 481)$ were selected as precursor ions, $(\mathrm{NaClNa})^{+}\left(m / z\right.$ 81), $(\mathrm{NaClCs})^{+}(m / z 191),(\mathrm{CsClCs})^{+}$ $(m / z 301), \mathrm{Na}^{+}(m / z 23), \mathrm{Cs}^{+}(m / z \text { 133), (D-Glu }+\mathrm{Na})^{+}$ $(m / z 203)$, and (D-Glu $+\mathrm{Cs})^{+}(m / z 313)$ were observed as intense peaks [Figs. 2(a), (b), and (c)]. According to the CAD results, $(\mathrm{NaClNa})^{+}(m / z 81),(\mathrm{NaClCs})^{+}(m / z 191)$, 


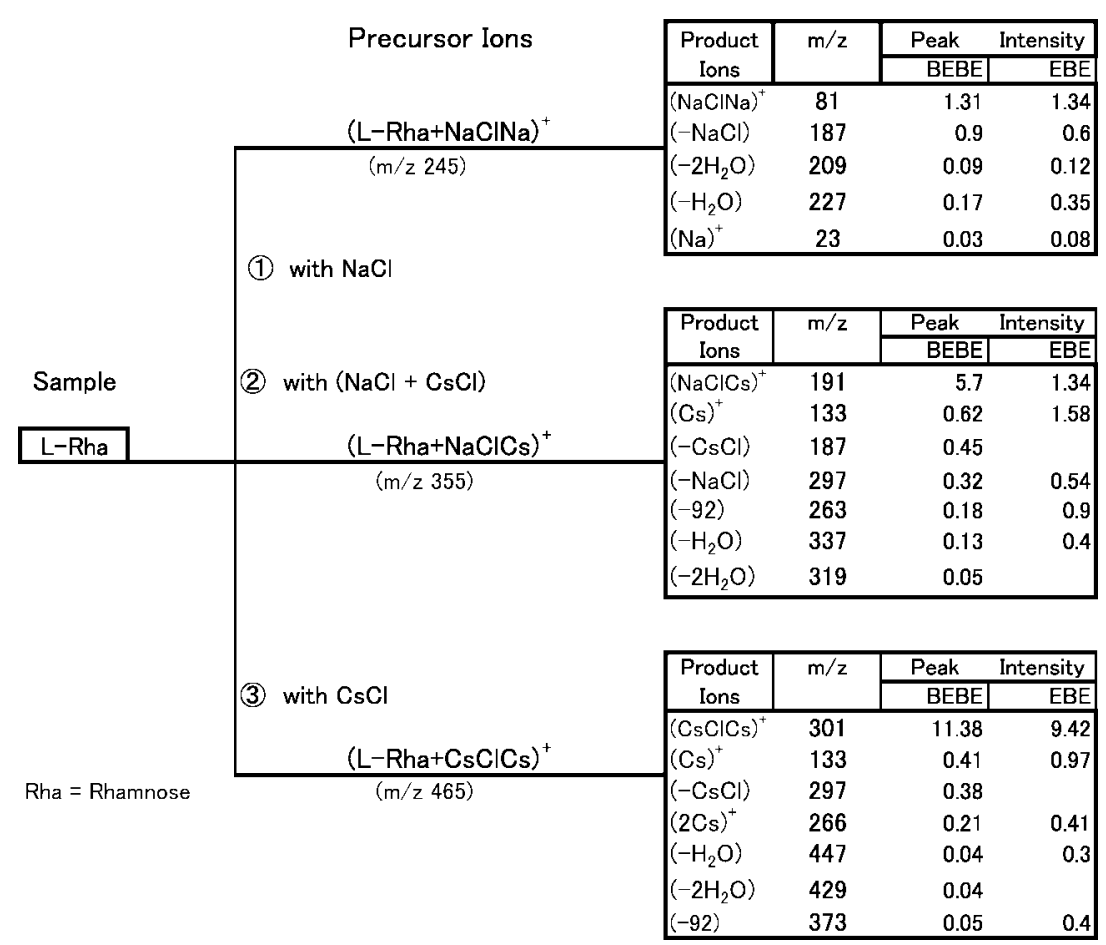

Fig. 3e. Peak intensities of product ions from $(\mathrm{Rha}+\mathrm{NaClNa})^{+}(m / z 245)$, $(\mathrm{Rha}+\mathrm{NaClCs})^{+}(m / z 355)$, and $(\mathrm{Rha}+\mathrm{CsClCs})^{+}$ $(m / z 465)$ obtained by CAD.

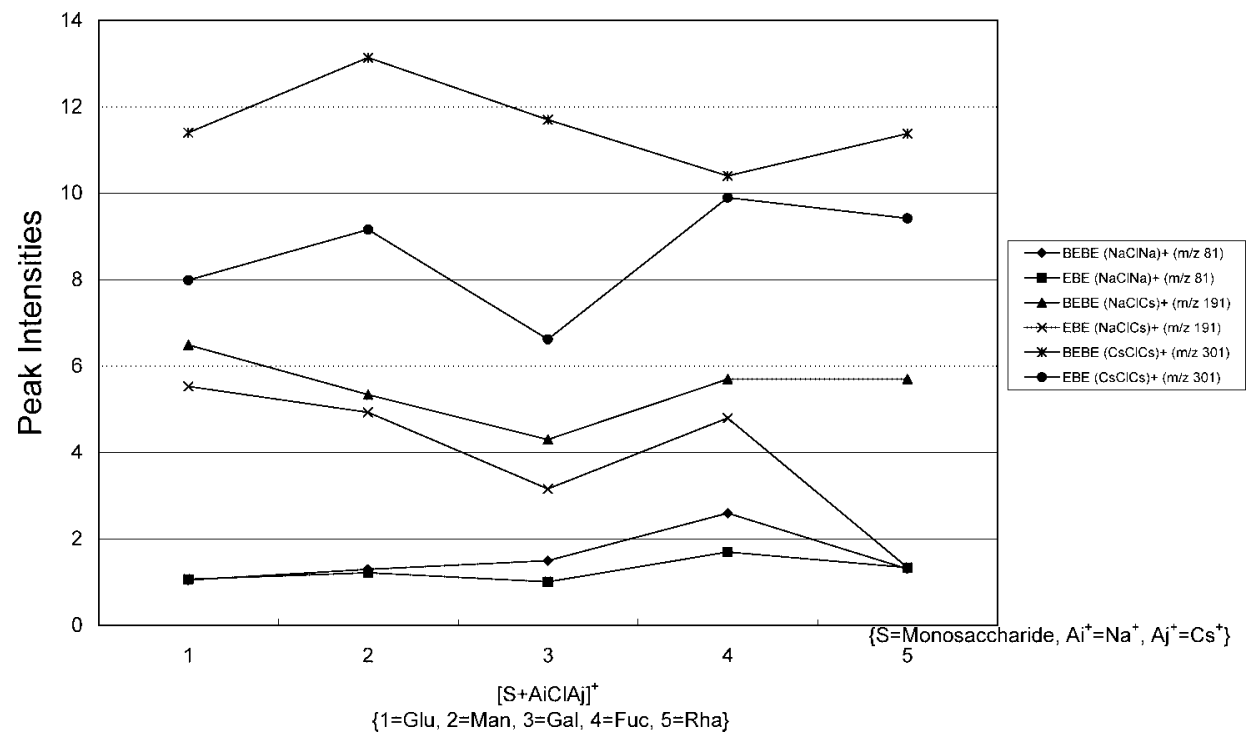

Fig. 4. Comparison of the peak intensities of triple ions obtained by CAD, using BEBE and EBE type instruments.

and $(\mathrm{CsClCs})^{+}(\mathrm{m} / z$ 301) were the strongest peaks observed in each case [See Figs. 3(a), (b), (c), (d), and (e)]. In both BEBE and EBE type instruments, the intensities of the alkali halide triple ion peaks increased with their ion sizes: $(\mathrm{NaClNa})^{+}<(\mathrm{NaClCs})^{+}<(\mathrm{CsClCs})^{+}$(Fig. 4). In general, the main peak intensities in BEBE type instrument varied around $1.6 \%$ for $(\mathrm{NaClNa})^{+}, 5.5 \%$ for $(\mathrm{NaClCs})^{+}$and $11.6 \%$ for $(\mathrm{CsClCs})^{+}$, while in EBE varied around $1.3 \%, 4.0 \%$ and $8.6 \%$, respectively.

At this point, since the binding interactions between the monosaccharide molecules and the alkali halide triple ions are weak, the intensities of the triple ion peaks show that binding interactions existing in the alkali halide triple ions, $\left\{(\mathrm{AiXAi})^{+},(\mathrm{AiXAj})^{+}\right.$, and $\left.(\mathrm{AjXAj})^{+}\right\}$, are stronger than the binding interactions between the monosaccharide molecules and the triple ions. In other words, this result shows the stability of the alkali halide triple ions. Consequently, as can be seen in the mass spectra, peaks of alkali halide triple ions are more intense than peaks of adduct ions of monosaccharide molecules with alkali halide triple ions. The same tendency is observed in CAD spectra where the alkali halide triple ion does not suffer extensive fragmentation and remains as an alkali halide triple ion.

In most cases, the $\mathrm{Na}^{+}$peak did not appear in $\mathrm{CAD}$ spectra or its peak was very weak. This demonstrates that the binding interactions between the monosaccharide molecules and the alkali ions are stronger than the binding interactions between the mono- 


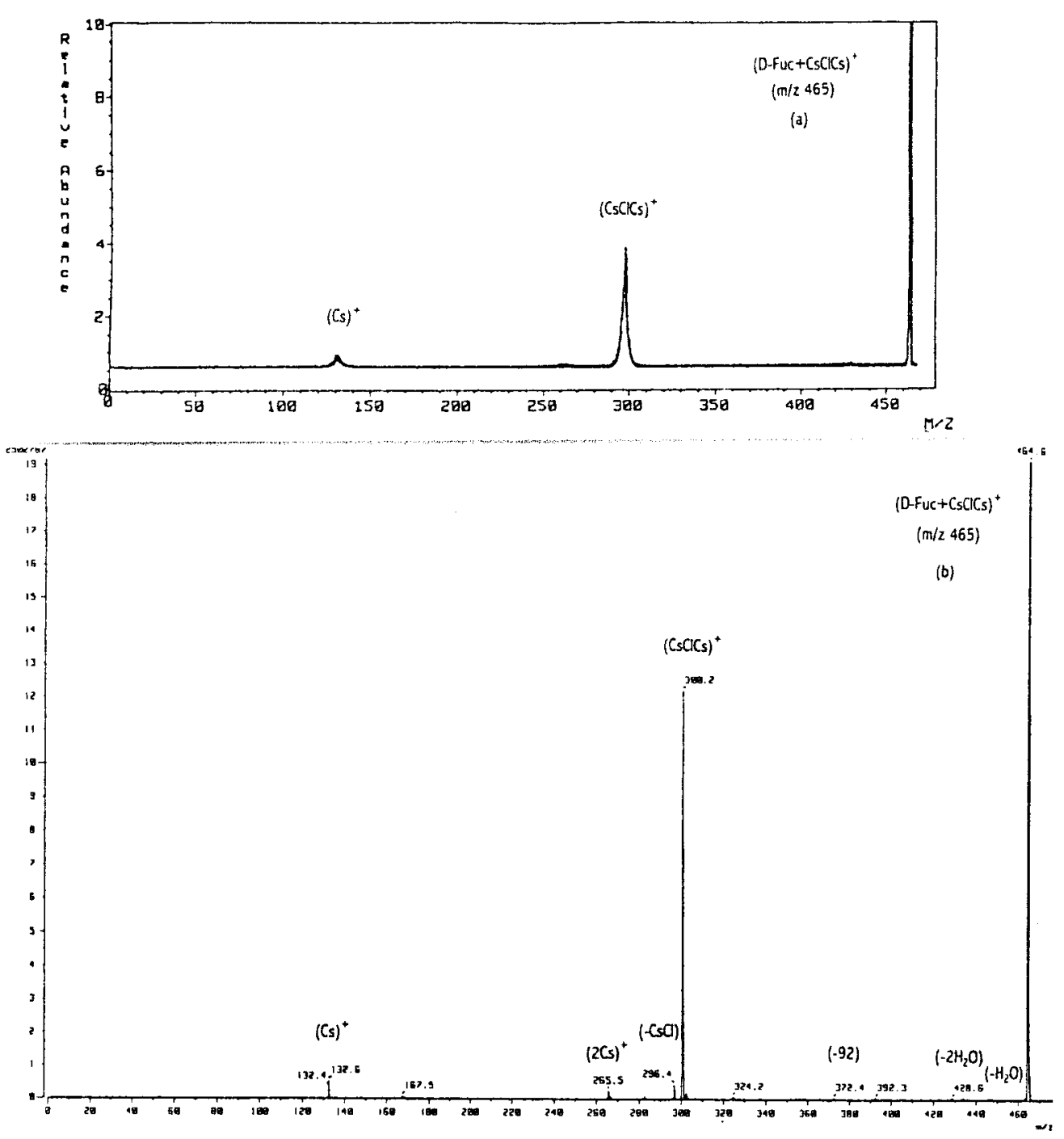

Fig. 5. FABMS/MS spectra of (D-Fucose $+\mathrm{CsClCs})^{+}(m / z$ 465) using (a) $\mathrm{EBE}$ and (b) BEBE type instruments.

saccharide molecules and the alkali halide triple ions. Moreover, it suggests that more energy is necessary to dissociate the alkali ion from $(\mathrm{AiXAj})^{+}$than the energy required to dissociate $(\mathrm{AiXAj})^{+}$from $(\mathrm{S}+\mathrm{AiXAj})^{+}$.

In the cases of Glu, Gal, and Man, peaks of $(B+$ $\mathrm{AiXAj})^{+}(\mathrm{B}=\mathrm{CHO}-\mathrm{HCOH}-\mathrm{CHO})$ were detected. On the other hand, in the cases of Fuc and Rha, very faint $(\mathrm{B}+$ AiXAj) ${ }^{+}$signals appeared (Fig. 5). It must be reported that judging from the CAD spectra of D- and L-type monosaccharide molecules (not shown here), the product ions and their intensities were very similar. No obvious differences were detected by CAD method.

In addition, as shown in Figs. 6(a) and (b), the peaks, due to loss of one or two water molecules from $(\mathrm{S}+$ $\mathrm{AiXAi})^{+},(\mathrm{S}+\mathrm{AiXAj})^{+}$, and $(\mathrm{S}+\mathrm{AjXAj})^{+}$, were observed. In most cases, the intensities of dehydration peaks like $\left[(\mathrm{S}+\mathrm{AiXAj})-\mathrm{H}_{2} \mathrm{O}\right]^{+}$and product ion peaks like $[(\mathrm{S}$ $\left.+\mathrm{AiXAj})^{+}-92\right]$ were more intense in EBE than in BEBE spectra. Also, it was observed that loss of water molecules from $(\mathrm{S}+\mathrm{NaClNa})^{+}$occurs more easily than dehydration from $(\mathrm{S}+\mathrm{NaClCs})^{+}$and $(\mathrm{S}+\mathrm{CsClCs})^{+}$. This result may be related to the alkali metal ion affinity for the monosaccharide molecules and the size of the alkali cations. Also, the peak intensities of $(\mathrm{NaClNa})^{+}$ions in the CAD spectra were weak. This result suggests that the $(\mathrm{NaClNa})^{+}$ion bonds to monosaccharide molecules more strongly than other alkali halide triple ions. Moreover, $(\mathrm{S}+\mathrm{NaClNa})^{+}$, as can be seen in the CAD spectra, dehydrated, and simultaneously, there was a very faint $\mathrm{Na}^{+}$peak. On the other hand, in the CAD spectra of $(\mathrm{S}+\mathrm{CsClCs})^{+}$, the dehydration peak was only slightly visible, and there was an intense $\mathrm{Cs}^{+}$peak. The relative intensities of the dehydration peaks varied from approximately $0.05 \%$ to $0.45 \%$, while the bi-dehydration peaks varied from $0.05 \%$ to $0.55 \%$. In all rhamnose systems like (Rha+ $\mathrm{NaClNa})^{+}$, $(\mathrm{Rha}+\mathrm{NaClCs})^{+}$, and $(\mathrm{Rha}+\mathrm{CsClCs})^{+}$, dehydration peak intensities varied from $0.05 \%$ to $0.35 \%$, while bi-dehydration peak intensities varied from $0.04 \%$ to $0.12 \%$ [Figs. 6(a), 6(b)].

The intensities of $(\mathrm{S}+\mathrm{Na})^{+}$peaks observed by BEBE were higher than those by EBE, and higher than $(\mathrm{S}+$ $\mathrm{Cs})^{+}$peaks observed by both $\mathrm{BEBE}$ and $\mathrm{EBE}$ measurements (except for $\{\mathrm{Glu}+\mathrm{NaClNa}\}^{+}$precursor ion). These results suggest that it is easier to take off a $\mathrm{CsCl}$ molecule from $(\mathrm{S}+\mathrm{NaClCs})^{+}$precursor ion than to take off a $\mathrm{NaCl}$ molecule from the same precursor ions. This can be related to the size of alkali cations and the binding interactions between the monosaccharide molecules and the alkali cations. Moreover, this result 


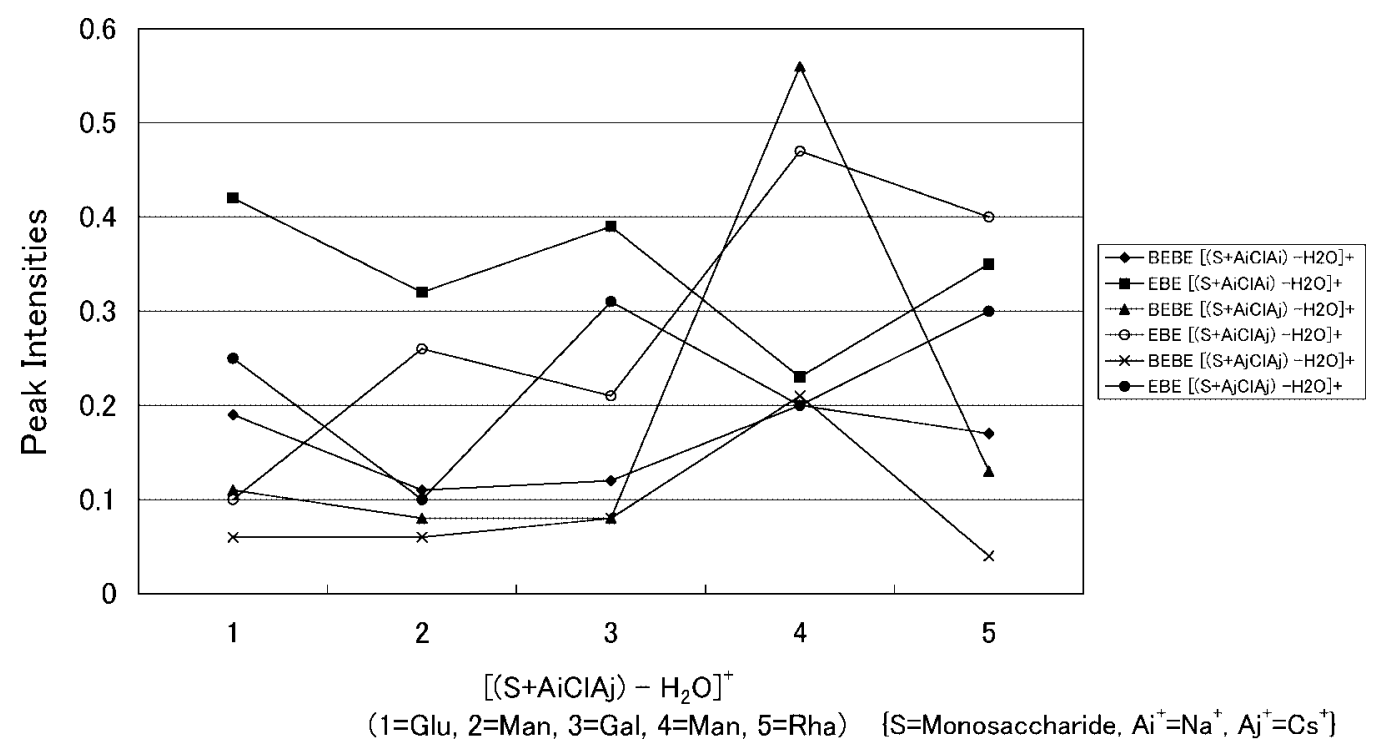

Fig. 6a. Comparison of the $\left[(\mathrm{S}+\mathrm{AiClAj})-\mathrm{H}_{2} \mathrm{O}\right]^{+}$peak intensities obtained by $\mathrm{CAD}$, using $\mathrm{BEBE}$ and EBE type instruments.

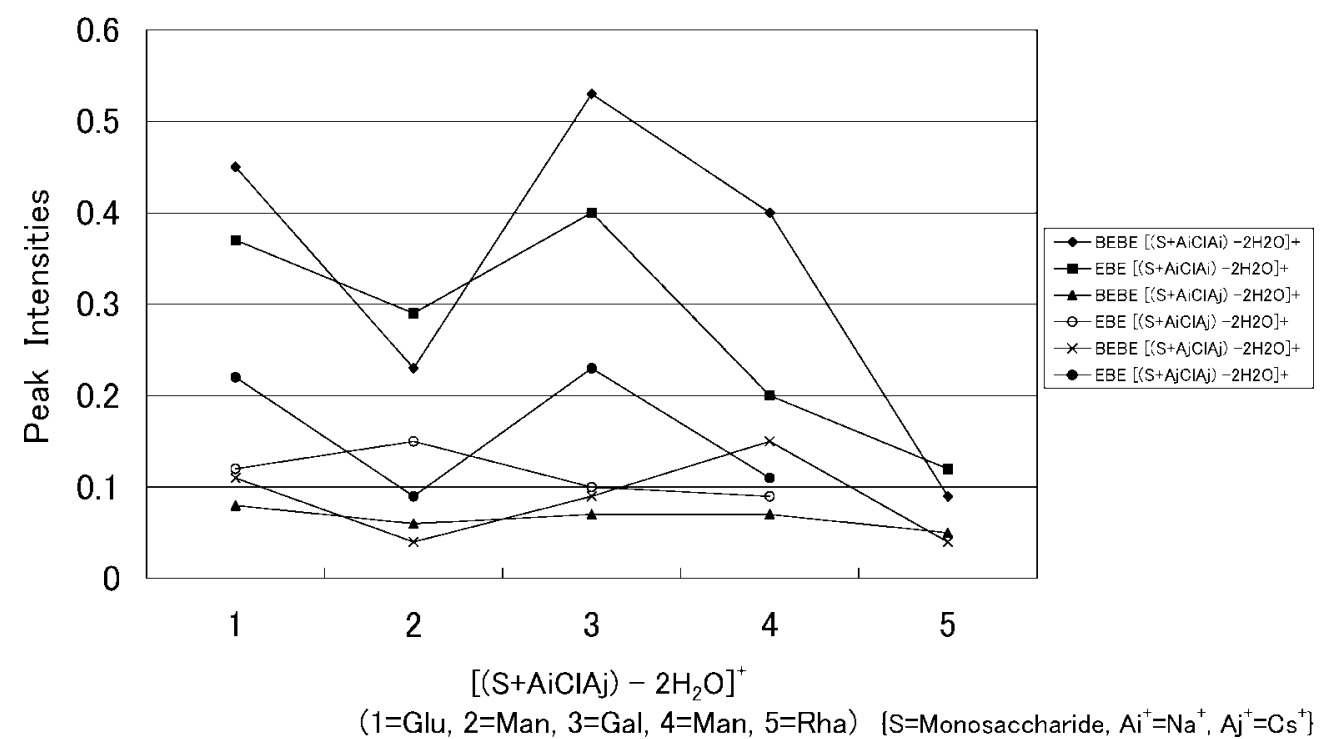

Fig. 6b. Comparison of the $\left[(\mathrm{S}+\mathrm{AiClAj})-2 \mathrm{H}_{2} \mathrm{O}\right]^{+}$peak intensities obtained by $\mathrm{CAD}$, using $\mathrm{BEBE}$ and EBE type instruments.

shows that it needs more energy to dissociate a $\mathrm{NaCl}$ molecule from the $(\mathrm{S}+\mathrm{NaClCs})^{+}$precursor ions than to dissociate a $\mathrm{CsCl}$ molecule from the same precursor ions. We can represent the fragmentation processes as follows: $\left\{(\mathrm{S}+\mathrm{NaClCs})^{+} \rightarrow(\mathrm{S}+\mathrm{Na})^{+}\right.$(higher intensity) + $\mathrm{CsCl}\}$, and $\left\{(\mathrm{S}+\mathrm{NaClCs})^{+} \rightarrow(\mathrm{S}+\mathrm{Cs})^{+}\right.$(lower intensity) $+\mathrm{NaCl}\}$. In most cases, in the metastable ion (MI) spectra of $(\mathrm{S}+\mathrm{NaClNa})^{+}$(not shown here), the intensity of the peak due to dehydration was more intense than that of $(\mathrm{NaClNa})^{+}$.

As it is known, a number of product ions in CAD spectra reflect a difference between protonated and alkali cationized monosaccharide molecules. Moreover, under similar ionization conditions, small alkali cations like $\mathrm{Na}^{+}$produce a larger number of product ions than larger alkali ions like $\mathrm{Cs}^{+}$, since $\mathrm{Cs}^{+}$is not as strongly bound. In addition, a number of product ions depend on the strength of the metal ion-monosaccharide molecule interactions. ${ }^{2), 9)}$ In this respect, we can say that in the case of small alkali halide triple ion adduct of monosaccharide molecules (e.g. (Glu+ $\mathrm{NaClNa})^{+}$), the number of product ion peaks were larger, however, the intensities of the product ion peaks were less intense than the intensities of the product ions from the adduct ions of monosaccharides with large alkali halide triple ions (e.g. $\left.(\mathrm{Glu}+\mathrm{CsClCs})^{+}\right)$.

\section{Conclusion}

According to the results seen in the CAD spectra of both $\mathrm{BEBE}$ and $\mathrm{EBE}$ type instruments, the intensities of the alkali halide triple ion peaks increased with their ion sizes: $(\mathrm{NaClNa})^{+}<(\mathrm{NaClCs})^{+}<(\mathrm{CsClCs})^{+}$. The results were related to the alkali metal ion affinity for the monosaccharide molecules and the size of the alkali cations. Also, this result indicates that binding interactions existing in the halide triple ions are stronger than binding interactions between monosaccharide molecules and alkali halide triple ions. The loss of water 
molecules from $(\mathrm{S}+\mathrm{NaClNa})^{+}$occurred more easily than dehydration from $(\mathrm{S}+\mathrm{NaClCs})^{+}$and $(\mathrm{S}+\mathrm{CsClCs})^{+}$. Bi-dehydration peaks were easily observed in the $(\mathrm{S}+$ $\mathrm{NaClNa})^{+} \mathrm{CAD}$ spectra, whereas those in the $(\mathrm{S}+$ $\mathrm{CsClCs})^{+}$were only very slightly visible. As for alkalicationized monosaccharide molecules, the number and intensity of product ions produced by CAD depends on the strength of the alkali halide triple ionmonosaccharide molecule interactions. Thus, in the cases of small alkali halide triple ion adduct monosaccharide molecule ions, the number of product ions were larger, however, the intensities of the product ion peaks were less intense than the intensities of the product ions from larger alkali halide triple ion adduct monosaccharide molecule ions. Nonetheless, we know that it is necessary to carry out a more detailed study of this point. Thus, we are considering extending this investigation to a study of alkali halide triple ion affinities for monosaccharide molecules in the near future.

\section{Acknowledgment}

Thanks to the staff of our laboratory for helpful discussions and suggestions. Also, thanks to Ms. Susan James for suggestions.

\section{References}

1) M. T. Cancilla, S. G. Penn, J. A. Carroll, and C. B. Lebrilla, J. Am. Chem. Soc., 118, 6736 (1996).
2) M. Cancilla, A. W. Wong, L. R. Voss, and C. Lebrilla, Anal. Chem., 71, 3206 (1999).

3) H. Desaire and J. Leary, Anal. Chem., 71, 4142 (1999).

4) I. Fangmark, A. Jansson, and B. Nilsson, Anal. Chem., 71, 1105 (1999).

5) J. A. Mcloskey (ed.), "Methods in Enzymology 193, Mass Spectrometry," Academic Press, San Diego (1990), p. 539.

6) M. P. Chiarelli and M. L. Gross, Int. J. Mass Spectrom. Ion Processes, 37, 52 (1987).

7) K. Isa, N. Martinez, R. Nakata, and K. Endo, J. Mass Spectrom. Soc. Jpn., 49, 51 (2001).

8) K. Isa and Y. Takeuchi, Org. Mass Spectrom., 24, 153 (1989).

9) L. C. Ngoka, J. Gal, and C. B. Lebrilla, Anal. Chem., 66, 692 (1994).

10) R. M. Silverstein and F.X. Webster, "Spectrometric Identification of Organic Compounds," New York (1966).

11) F. W. McLafferty and F. Turecek, "Interpretation of Mass Spectra," California (1993).

12) Z. Zhou, S. Ogden, and J. A. Leary, J. Org. Chem., 55, 5444 (1990).

13) D. Garozzo, M. Giuffrida, and G. Impallomeni, Anal. Chem., 62, 279 (1990).

Keywords: Monosaccharide molecules, Fast atom bombardment (FAB), Collisionally activated dissociation (CAD), Alkali halide triple ions, Precursor ions, Product ions, Adduct ions 